\title{
Molecular mechanisms of genetic variation and transcriptional regulation of CYP2C19
}

\author{
Nuala Ann Helsby* and Kathryn Elisa Burns \\ Molecular Medicine and Pathology, Faculty of Medical and Health Sciences, University of Auckland, Auckland, New Zealand
}

\author{
Edited by: \\ Kathrin Klein, Dr. Margarete \\ Fischer-Bosch-Institute of Clinical \\ Pharmacology, Germany \\ Reviewed by: \\ Kyung-Sang Yu, Seoul National \\ University College of Medicine and \\ Hospital, South Korea \\ Su-Jun Lee, Inje University College \\ of Medicine, South Korea \\ *Correspondence: \\ Nuala Ann Helsby, Molecular \\ Medicine and Pathology, Faculty of \\ Medical and Health Sciences, \\ University of Auckland, Private Bag \\ 92019, Auckland 1142, New Zealand. \\ e-mail:n.helsby@auckland.ac.nz
}

Inherited variation in the function of the drug metabolizing enzyme CYP2C19 was first observed 40 years ago. The SNP variants which underpin loss of CYP2C19 function have been elucidated and extensively studied in healthy populations. However, there has been relatively meagre translation of this information into the clinic. The presence of genotype-phenotype discordance in certain patients suggests that changes in the regulation of this gene, as well as loss of function SNPs, could play a role in deficient activity of this enzyme. Knowledge of the molecular mechanisms which control transcription of this gene, reviewed in this article, may aid the challenge of delivering CYP2C19 pharmacogenetics into clinical use.

Keywords: CYP2C19, pharmacogenetics, transcription factors, epigenetics, miRNA

\section{INTRODUCTION}

CYP2C19 is important in the metabolism of many clinically relevant drugs (Desta et al., 2002), particularly for several prodrugs that require hepatic activation including clopidogrel (Bauer et al., 2011; Begg et al., 2012). The first reports of an autosomal recessive inherited trait that resulted in poor metabolism of the prototypical CYP2C19 substrate, mephenytoin, appeared many years ago (Kupfer et al., 1979). The correlation between the poor metabolizer phenotype and loss of function genotype has been comprehensively studied in healthy populations (Desta et al., 2002). Screening for these genetic variants is one approach to individualize therapy for drugs which are substrates for this enzyme. However to be useful genotype must be predictive of phenotype, not only in healthy populations but also in the clinical context (Helsby, 2008). The presence of genotype-phenotype discordance in certain morbidities (Williams et al., 2000; Frye et al., 2002; Helsby et al., 2008), suggests that an acquired deficiency in the activity of this enzyme also occurs. Factors which regulate CYP2C19 transcription could play an additional role in the pharmacogenomic variation of this enzyme. The current knowledge of the molecular mechanisms which control expression of the CYP2C19 gene, such as the coding and regulatory region cisvariants as well as trans-acting epigenomic factors, are reviewed in this article.

\section{CYP2C19 GENE VARIANTS}

The role of cis-acting variants of CYP2C19 have been extensively characterized and the polymorphic expression of these genetic variants results in inter-individual variation in CYP2C19 activity. More than 28 variant alleles in CYP2C19 have been identified (http://www.cypalleles.ki.se/, access date August 19, 2012) and are summarized in Table 1. Many of these variants have relatively low frequency however, the SNPs which lead to the CYP2C19*2 and $\mathrm{CYP} 2 \mathrm{C} 19^{*} 3$ alleles are common and have been the most extensively studied. These SNPs, c.681G $>$ A, and c.636G $>$ A, cause aberrant splicing and a premature stop codon respectively and result in null function. Individuals who are homozygous variant for either of these alleles are poor metabolizers of certain drugs. The allele frequency of these null function variants varies with ethnicity (Xie et al., 2001; Sistonen et al., 2009). A particularly high prevalence of both *2 and *3 is observed in Vanuatu and Papua New Guinea, accounting for up to $70.8 \%\left({ }^{*} 2\right)$ and $13.3 \%(* 3)$ of these alleles in the Vanuatu population, and up to $42.3 \%$ and $31.5 \%$, respectively, in the Papua New Guinea population (Kaneko et al., 1997; Hsu et al., 2008). This exceptionally high expression in Melanesia may reflect an unidentified evolutionary pressure. For further information on these null function alleles and the drug substrates of CYP2C19 readers are directed to review articles that have focused on CYP2C19 pharmacogenetics such as Desta et al. (2002). In addition to genetic variation in the coding region of the gene, promoter region variation may also influence transcriptional expression and ultimately activity. The $C Y P 2 C 19^{*} 17$ allele (g. $-3402 \mathrm{C}>\mathrm{T}$ and g. $-806 \mathrm{C}>\mathrm{T}$ ) has been the focus of studies to identify increased function variants of this gene. Ethnic variation in the prevalence of this allele is also observed with a relatively low allele frequency $(<5 \%)$ in Japanese and Chinese populations, compared with a higher incidence in European and African populations ( $\sim 15-30 \%)$ (Li-Wan-Po et al., 2010).

\section{REGULATORY POLYMORPHISMS CYP2C19: 17}

CYP2C19*17 was first identified in 2006 (Sim et al., 2006). Electrophoretic mobility shift assays (EMSA) detected binding of human hepatic nuclear proteins at $-806 \mathrm{~T}$ but not $-806 \mathrm{C}$. A potential GATA binding site at this position was identified 
Table 1 | CYP2C19 gene variants.

\begin{tabular}{|c|c|c|c|c|c|}
\hline \multirow[t]{2}{*}{ Allele } & \multicolumn{3}{|c|}{ Characteristic SNPa } & \multirow[t]{2}{*}{ Functional change } & \multirow[t]{2}{*}{ References } \\
\hline & cDNA & Gene & Effect & & \\
\hline CYP2C $19 * 1$ & None $^{1}$ & None & None & Normal & Romkes et al., 1991 \\
\hline CYP2C19*2 & $681 G>A^{2}$ & $19154 G>A$ & Splicing defect & Non-functional & $\begin{array}{l}\text { De Morais et al., 1994b; Ibeanu et al., } \\
\text { 1998b; Fukushima-Uesaka et al., 2005; } \\
\text { Lee et al., 2009; Satyanarayana et al., } \\
\text { 2009a }\end{array}$ \\
\hline CYP2C19*3 & $636 \mathrm{G}>\mathrm{A}^{3}$ & $17948 G>A$ & $\begin{array}{l}\text { Premature stop codon } \\
(\text { W212X) }\end{array}$ & Non-functional & $\begin{array}{l}\text { De Morais et al., 1994a; } \\
\text { Fukushima-Uesaka et al., } 2005\end{array}$ \\
\hline CYP2C19*4 & $1 \mathrm{~A}>\mathrm{G}^{4}$ & $1 A>G$ & GTG initiation codon & Non-functional & Ferguson et al., 1998; Scott et al., 2011 \\
\hline CYP2C19*5 & $1297 \mathrm{C}>\mathrm{T}^{5}$ & $90033 C>T$ & R433W & Non-functional & Xiao et al., 1997; Ibeanu et al., 1998a \\
\hline CYP2C19*6 & $395 G>A$ & $12748 \mathrm{G}>\mathrm{A}$ & $\mathrm{R} 132 \mathrm{O}$ & Non-functional & Ibeanu et al., 1998b \\
\hline CYP2C19*7 & & $19294 \mathrm{~T}>\mathrm{A}$ & Splicing defect & Non-functional & Ibeanu et al., 1999 \\
\hline CYP2C19*8 & $358 \mathrm{~T}>\mathrm{C}$ & $12711 \mathrm{~T}>\mathrm{C}$ & W120R & Decreased in vitro & Ibeanu et al., 1999 \\
\hline CYP2C19*9 & $431 \mathrm{G}>\mathrm{A}$ & $12784 \mathrm{G}>\mathrm{A}$ & $\mathrm{R} 144 \mathrm{H}$ & Decreased in vitro & Blaisdell et al., 2002 \\
\hline CYP2C19*10 & $680 \mathrm{C}>\mathrm{T}$ & $19153 C>T$ & P227L & Decreased in vitro & Blaisdell et al., 2002 \\
\hline CYP2C19*11 & $449 G>A$ & $12802 \mathrm{G}>\mathrm{A}$ & $\mathrm{R} 150 \mathrm{H}$ & Similar to wild type in vitro & Blaisdell et al., 2002 \\
\hline CYP2C19*12 & $1473 A>C$ & $90209 A>C$ & $\begin{array}{l}\text { X491C; } 26 \text { extra amino } \\
\text { acids }\end{array}$ & Unstable in vitro & Blaisdell et al., 2002 \\
\hline CYP2C19*13 & $1228 \mathrm{C}>\mathrm{T}$ & $87290 \mathrm{C}>\mathrm{T}$ & $\mathrm{R} 410 \mathrm{C}$ & Similar to wild type in vitro & Blaisdell et al., 2002 \\
\hline CYP2C19*14 & $50 T>C$ & $50 \mathrm{~T}>\mathrm{C}$ & L17P & Not determined & Blaisdell et al., 2002 \\
\hline CYP2C19*15 & $55 \mathrm{~A}>\mathrm{C}$ & $55 \mathrm{~A}>\mathrm{C}$ & $\mid 19 \mathrm{~L}$ & Not determined & Blaisdell et al., 2002 \\
\hline CYP2C19*16 & $1324 \mathrm{C}>\mathrm{T}^{6}$ & $90060 \mathrm{C}>\mathrm{T}$ & $\mathrm{R} 442 \mathrm{C}$ & Not determined & Morita et al., 2004 \\
\hline CYP2C19*17 & & $\begin{array}{l}3402 \mathrm{C}>\mathrm{T} \\
-806 \mathrm{C}>\mathrm{T}\end{array}$ & & $\begin{array}{l}\text { Increased transcription } \\
\text { in vitro; Should not be termed } \\
\text { Ultrarapid (UM) }\end{array}$ & Sim et al., 2006 \\
\hline CYP2C19*18 & $986 \mathrm{G}>\mathrm{A}$ & $\begin{array}{l}80156 \mathrm{G}>\mathrm{A} \\
87106 \mathrm{~T}>\mathrm{C}\end{array}$ & $\mathrm{R} 329 \mathrm{H}$ & Not determined & Fukushima-Uesaka et al., 2005 \\
\hline CYP2C19*19 & $151 A>G$ & $\begin{array}{l}151 \mathrm{~A}>\mathrm{G} \\
87106 \mathrm{~T}>\mathrm{C}\end{array}$ & S51G & Not determined & Fukushima-Uesaka et al., 2005 \\
\hline CYP2C $19 * 20^{7}$ & $636 \mathrm{G}>\mathrm{A}$ & $17948 G>A$ & $\begin{array}{l}\text { Premature stop codon } \\
\text { (W212X) and D360N }\end{array}$ & Non-functional & Fukushima-Uesaka et al., 2005 \\
\hline CYP2C $19 * 21^{8}$ & $681 \mathrm{G}>\mathrm{A}$ & $\begin{array}{l}19154 G>A \\
-98 T>C\end{array}$ & $\begin{array}{l}\text { splicing defect and } \\
\text { A161P }\end{array}$ & Non-functional & $\begin{array}{l}\text { Fukushima-Uesaka et al., 2005; } \\
\text { Satyanarayana et al., 2009a }\end{array}$ \\
\hline CYP2C19*22 & $557 \mathrm{G}>\mathrm{C}$ & $17869 \mathrm{G}>\mathrm{C}$ & $\mathrm{R} 186 \mathrm{P}$ & Not determined & Matimba et al., 2009 \\
\hline CYP2C19*23 & $271 G>C$ & $12455 G>C$ & G91R & Not determined & Zhou et al., 2009 \\
\hline CYP2C19*24 & $\begin{array}{l}1004 G>A \\
1197 A>G\end{array}$ & $\begin{array}{l}80174 G>A \\
87259 A>G\end{array}$ & R3350 & Not determined & Zhou et al., 2009 \\
\hline CYP2C19*25 & $1344 C>G$ & $90080 \mathrm{C}>\mathrm{G}$ & F448L & Not determined & Zhou et al., 2009 \\
\hline CYP2C19*26 & $766 \mathrm{G}>\mathrm{A}$ & $19239 G>A$ & D256N & Decreased in vitro & Lee et al., 2009 \\
\hline CYP2C19*27 & & $-1041 G>A$ & & Decreased in vitro & Drögemöller et al., 2010 \\
\hline CYP2C19*28 & $1120 \mathrm{G}>\mathrm{A}$ & $\begin{array}{l}-2020 \mathrm{C}>\mathrm{A} \\
-1439 \mathrm{~T}>\mathrm{C} \\
80290 \mathrm{G}>\mathrm{A}\end{array}$ & V374I & $\begin{array}{l}\text { No significant decrease } \\
\text { in vitro }\end{array}$ & Drögemöller et al., 2010 \\
\hline
\end{tabular}

a Only major SNP or alteration(s) responsible for the phenotype of the corresponding allele are shown. Adapted from http://www.cypalleles. ki.se/

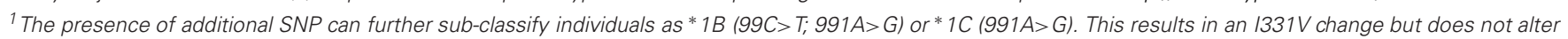
activity.

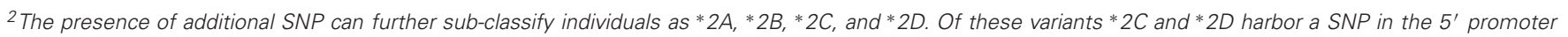
region $(-98 T>C)$ that may have a functional effect.

${ }^{3}$ The presence of additional SNP can further sub-classify individuals as * $3 A(1251 A>C)$ and * 3B $(1078 G>A ; 1251 A>C)$.

${ }^{4}$ The presence of $-3402 C>T ;-806 C>T S N P$ in the promoter can further sub-classify individuals as * 4B.

${ }^{5}$ The presence of $99 C>T ; 991 A>G$, can further sub-classify individuals as * $5 B$.

${ }^{6}$ Existence of the CYP2C19*2 polymorphism 681G>A on the same allele cannot be excluded.

${ }^{7}$ Also known as CYP2C19*3B.

${ }^{8}$ Also known as CYP2C19*2C. 
in silico and it was hypothesized that the $-806 \mathrm{C}>\mathrm{T}$ variant could result in increased transcription of CYP2C19. However, to date GATA-dependent transactivation at the $-806 \mathrm{C}>\mathrm{T}$ site has not been directly demonstrated. Indeed it is of note that following co-transfection with GATA-4 or GATA-6, -806T $>$ C variant reporter constructs did not have increased luciferase activity compared with wildtype constructs (Mwinyi et al., 2010b). Although GATA may not be involved, transfection of reporter constructs of the $-0.9 \mathrm{~Kb}$ of the $5^{\prime}$ flanking region into mice lead to an increase in transcription in the $-806 \mathrm{~T}$ mutant compared with wildtype construct. However a range of overlapping individual luciferase activities were observed in wildtype and mutant constructs. To date no direct evidence of correlations between $C Y P 2 C 19^{*} 17$ genotype status and increased transcription or protein expression in human liver biobanks has been reported. Despite the lack of direct evidence this genotype is often described as increasing the expression of the enzyme (protein) and many investigators have categorized individuals who carry this variant allele as ultrarapid metabolizers (UM). When CYP2C19 activity is measured in vivo using drug to metabolite ratios of probe substrates such as omeprazole it is clear that the mean activity of CYP2C19 is higher in homozygous $* 17 /^{*} 17$ subjects than in individuals with the ${ }^{*} 1 /{ }^{*} 1$ genotype (Baldwin et al., 2008). However, the activity in ${ }^{*} 17 / /^{*} 17$ subjects overlaps the heterogenous activity observed in ${ }^{*} 1 /^{*} 1$ subjects (Baldwin et al., 2008). Similar effects have been observed with other drugs such as escitalopram, clopidogrel and voriconazole (Li-Wan-Po et al., 2010). The high activity in some ${ }^{*} 1 /^{*} 1$ subjects may be due to other currently unidentified increased activity variants. However currently $* 17 / * 17$ subjects do not appear to be a separate population and fall within the normal distribution of wildtype CYP2C19 activity, therefore should not be classified as an ultra-rapid phenotype. Moreover, the ultrarapid metabolizer phenotype observed with CYP2D6 substrates is typically due to gene duplication and associated copy number variation, and it is important to note that copy number variation for CYP2C19, appears to be absent (Drögemöller et al., 2010; Devendran et al., 2012). Further identification of additional SNP in the $5^{\prime}$-up-stream region of CYP2C19 may clarify the wide heterogeneity of activity in ${ }^{*} 1 /^{*} 1$ individuals.

\section{OTHER PROMOTER REGION VARIANTS}

Publication of the promoter sequence of CYP2C19 gene (Genbank accession \#AF354181) led to the identification of eight $\mathrm{SNP}$ in the $-1.833 \mathrm{~Kb}$ promoter region (Arefayene et al., 2003). Resequencing of genomic DNA from 92 individuals of varied ethnicity identified $13 \mathrm{SNP}$ in the $-1.46 \mathrm{~Kb}$ up-stream region of the gene (Blaisdell et al., 2002). Extensive characterization of the $5^{\prime}$-regulatory region of CYP2C19 also identified a further seven SNP novel variants in the enhancer region and five SNP in the promoter region in Japanese subjects (Fukushima-Uesaka et al., 2005). Eight novel SNP were also detected in the $-1.7 \mathrm{~Kb}$ promoter region in a South Indian population (Satyanarayana et al., 2009b). More recently resequencing of $-2.095 \mathrm{~Kb}$ of the $5^{\prime}$-up-stream region of CYP2C19 identified two additional novel SNP (g.-2030C > T and g.-2020C >A). These SNPs, in combination with a previously identified SNP in the 5'promoter (g. $-1439 \mathrm{~T}>\mathrm{C}$ ) and the g.80290 G>A SNP in exon 7, result in the CYP2C19*28 genotype (Table 1) (Drögemöller et al., 2010). Extensive ethnic variation in the frequency of promoter/enhancer region SNP is evident from the above studies. Identification of the functional effects of these 35 novel SNP identified up-stream of the translational start site is important for our understanding of the variable expression and activity of this enzyme.

Regions of negative and positive regulatory control of CYP2C19 were observed following transient expression of luciferase reporter deletion constructs in HepG2 cells (Arefayene et al., 2003). Transient expression into HepG2 cells of luciferase reporter deletion constructs between positions $-153 \mathrm{bp}$ and $-17 \mathrm{bp}$ significantly decreased luciferase activity, suggesting effects on transcription factor binding. In contrast deletion from $-650 \mathrm{bp}$ to $-363 \mathrm{bp}$ increased luciferase activity, indicating the presence of repressor regulation in this region. Using nine different constructs of the CYP2C19 $5^{\prime}$ promoter region $(-1.6 \mathrm{~Kb})$ transfected into HepG2 cells, Satyanarayana et al. (2011) showed that the presence of either the -98T >C SNP in combination with $-1498 \mathrm{~T}>\mathrm{G}$ or the combination of $-98 \mathrm{~T}>\mathrm{C}$, $-779 \mathrm{~A}>\mathrm{C},-1051 \mathrm{~T}>\mathrm{C}$, and $-1418 \mathrm{C}>\mathrm{T}$, significantly increased luciferase activity. The SNP $-98 \mathrm{~T}>\mathrm{C}$ is within both a potential CCAAT displacement protein (CDP) binding site and a potential GATA-1 site (Satyanarayana et al., 2009b). In silico analysis indicated that interaction of the CDP repressor with its putative binding site was weaker in the presence of the $-98 \mathrm{C}$ variant whereas GATA-1 had a high predicted binding activity in the presence of the normal $-98 \mathrm{~T}$. Hence the functional consequence may be that in wildtype subjects ( $-98 \mathrm{TT}$ or CT) repression of GATA-1 binding will be greater than in homozygous -98CC subjects. Indeed, the presence of -98TT genotype appears to decrease the activity of the enzyme compared with the -98CT or -98CC genotype in subjects probed in vivo with proguanil (Satyanarayana et al., 2009a). This is suggestive of a functional effect of a transcriptional repressor at this region of the promoter, in agreement with the early data from Arefayene et al. (2003). It is of interest to note that $-98 \mathrm{~T}>\mathrm{C}$ displays linkage with the c.681G $>$ A (*2) SNP (Fukushima-Uesaka et al., 2005; Satyanarayana et al., 2009b) as CYP2C19*21, also known as CYP2C19*2C (Table 1).

Most recently the g. $-1041 \mathrm{G}>\mathrm{A}$ SNP in the CYP2C19*27 allele (Table 1) has also been demonstrated to have functional consequences. Significantly decreased luciferase activity was observed in a construct transfected into HepG2 cells, whereas the promoter region SNP $(-2030 \mathrm{C}>\mathrm{T} ;-1439 \mathrm{~T}>\mathrm{C})$ in the CYP2C19*28 allele did not significantly decrease activity (Drögemöller et al., 2010). Thus, to date only three of the 35 SNP identified in the proximal five region of CYP2C19 appear to be associated with changes in gene transcription: $-806 \mathrm{C}>\mathrm{T} \quad\left({ }^{*} 17\right), \quad-1041 \mathrm{G}>\mathrm{A} \quad\left({ }^{2} 27\right)$ and $-98 \mathrm{~T}>\mathrm{C}(* 21)$.

\section{TRANSCRIPTION FACTOR BINDING SITES IN CYP2C19}

Many predicted or putative sites for transcription factor binding have been reported for CYP2C19. However, functional transcription factor binding sites have only been demonstrated for the ligand activated nuclear receptors $\mathrm{ER} \alpha$ (NR3A1) (Mwinyi et al., 2010a), CAR (NR1I3), and GR (NR3C1) (Chen et al., 2003), and 
the transcription factors HNF3 $\gamma$ (FOXA3) (Bort et al., 2004) and GATA-4 (Mwinyi et al., 2010b), (Figure 1).

The constitutive androstane receptor response element (CAR-RE) at $-1891 /-1876$ in the promoter region of CYP2C19 has been shown to functionally active. Binding of CAR protein occurs as a monomer or heterodimer with the retinoid $\mathrm{X}$ receptor (RXR) and pregnane $\mathrm{X}$ receptor (PXR). Deletion of this site completely abolishes binding (Chen et al., 2003). Expression of CYP2C19 appears to be more sensitive to the effects of cotransfection with CAR than with PXR, nevertheless luciferase activity can be induced by the PXR activator rifampicin (Chen et al., 2003), a known inducer of CYP2C19 activity in patients (Feng et al., 1998). There is a significant correlation between CAR mRNA and CYP2C19 transcription in human liver (Wortham et al., 2007). Deletion constructs have demonstrated the functional activity of a glucocorticoid responsive element (GRE) at $-1750 /-1736 \mathrm{~b}$, and dexamethasone can also induce the expression of a CYP2C19 construct containing this GRE in transfected HepG2 and Caco 2 cells (Chen et al., 2003).

A functional estrogen response element (ERE) half site has been identified in CYP2C19 at position -151/-147 (Mwinyi et al., 2010a). This GGTCA motif binds ER $\alpha$ but not ER $\beta$. Both $17-\beta$ estradiol and 17- $\alpha$ ethinylestradiol down-regulate reporter luciferase activity in Huh-7 transfected cells co-transfected with $\mathrm{ER} \alpha$. However, the partial agonists 4-hydroxytamoxifen and raloxifene had no effect on CYP2C19 transcription (Mwinyi et al., 2010a). Interestingly mutation of this ERE half site decreases but does not abolish luciferase activity. Chromatin immunoprecipitation of Huh-7 cells combined with q-PCR demonstrated that ER $\alpha$ was associated with this ERE half site in the CYP2C19 promoter. 17- $\alpha$ ethinylestradiol stimulated this interaction of ER $\alpha$ with the promoter whereas 4-hydroxytamoxifen abolished the interaction. Preliminary data suggested that treatment of primary hepatocytes with 17- $\beta$ estradiol or 17- $\alpha$ ethnylestradiol decreased CYP2C19
mRNA expression (Mwinyi et al., 2010a). This is in contrast to recent data which found that estradiol did not influence the expression of CYP2C19 (Choi et al., 2012). The biotransformation of estrogens by CYP enzymes results in a half-life of estradiol in human hepatocytes of $<34 \mathrm{~min}$. Thus concentration dependent ligand binding may influence transactivation of CYP2C19 by $\mathrm{ER} \alpha$ in hepatocytes.

In addition to the three ligand-activated transcription factors described above, two additional transcription factor proteins have also been demonstrated to be important in CYP2C19 transcription:- FOXA3 and GATA-4. Three hepatocyte nuclear factor 3 gamma (HNF3 $\gamma)$ sites, (-313/-298, -560/-545, $-623 /-608)$, have been identified in the CYP2C19 promoter (Bort et al., 2004). Cotransfection with HNF3 $\gamma$ in luciferase reporter assays as well as overexpression of HNF3 $\gamma$ in HeLa and hepatoma cells significantly increased expression of CYP2C19 (Bort et al., 2004). HNF3 $\gamma$ is member of the forkhead box/winged helix family of transcription factors and is also known as FOXA3. This transcription factor is important in the expression of liverspecific genes and the development of hepatic lineage. In contrast, co-transfection with $\mathrm{HNF} 4 \alpha$, did not increase luciferase expression despite the presence of HNF4 $\alpha$ sites at $-186 /-174$, $-152 /-140$ (Kawashima et al., 2006). These sites do not appear to be functional as deletion constructs, indicating that HNF4 $\alpha$ cannot increase transcription of CYP2C19 (Bort et al., 2004) and also indicate that HNF4 $\alpha$ protein does not bind to CYP2C19 (Bort et al., 2004; Rana et al., 2010).

GATA-4 is a member of the zinc-finger transcription factor family. Two adjacent GATA binding motifs (TATC) have been detected in the CYP2C19 promoter at $-165 /-162$ and -159/-156 (Mwinyi et al., 2010b). Wildtype and deletion constructs containing destructive mutations in each of the GATA sites were transfected into HepG2 or Huh-7 cells. Significant up-regulation of luciferase activity of these constructs

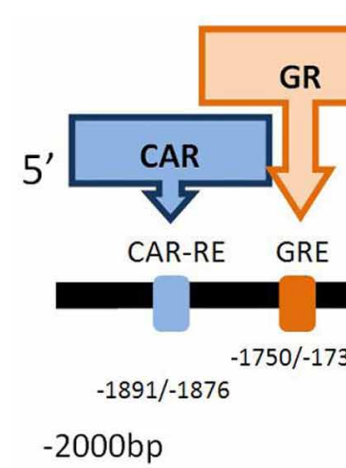

FIGURE 1 | Functional transcription factor binding sites in the $2.0 \mathbf{~ k b}$ $\mathbf{5}^{\prime}$-promoter region of CYP2C19. The binding factor CAR (constitutive androstane receptor; NR113) acts at the CAR response element (-1891/-1876 bp). NR113 can also hetero-dimerise with retinoid $X$ receptor $(\mathrm{RXR})$ and pregnane $\mathrm{X}$ receptor (PXR) to transactivate CYP2C19 (Chen et al., 2003). The glucocorticoid receptor (GR; NR3C1) acts at the glucocorticoid response element (GRE) at position -1750/-1736bp (Chen et al., 2003) Hepatocyte nuclear factor 3 gamma (HNF3 $\gamma$ ) is member of the forkhead box/winged helix family of transcription factors and is also known as FOXA3.

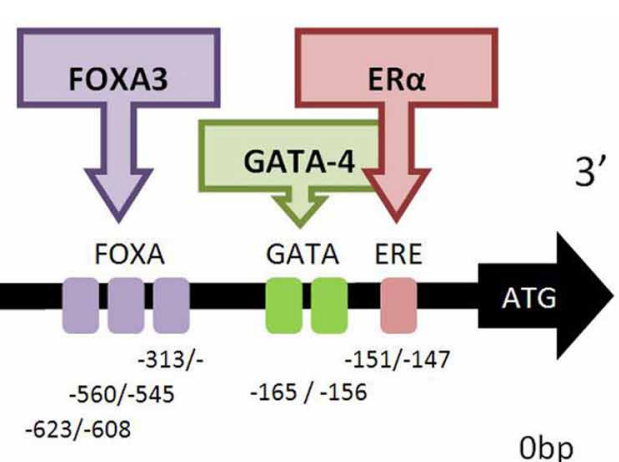

Three functional FOXA3 sites, (-313/-298, -560/-545, -623/-608bp) exist in the CYP2C19 promoter (Bort et al., 2004). GATA-4 is a member of the zinc-finger transcription factor family. Two adjacent GATA binding motifs (TATC) are found between -165/-156 bp, and GATA-4 predominantly binds to site I (-165/-162 bp). The repressor protein, Friend of GATA (FOG-2), attenuates the effect of GATA-4 binding (Mwinyi et al., 2010b). Estrogen receptor- $\alpha(E R \alpha)$ binds to the estrogen receptor element (ERE) half site at $-151 /-147 \mathrm{bp}$. Mutation of this site decreases but does not abolish transcription (Mwinyi et al., 2010a). 
was observed when co-transfected with either GATA-4 or GATA2. Deletion of this double GATA binding site completely abolished transcription. However, EMSA analysis demonstrated nuclear extracts predominantly bind to site I $(-165 /-162)$ and chromatin immunoprecipitation confirmed that GATA-4 was associated with the CYP2C19 promoter. The GATA repressor protein friend of GATA 2 (FOG-2), also known as zinc finger protein multitype-2, attenuates the effect of GATA-4 and may also have a role to play in the regulation of CYP2C19 transcription. GATA4 is an important liver associated transcription factor (Molkentin, 2000).

More recently, it has been proposed that the following transcription factors and binding sites may also be important in the transcription of CYP2C19:- ATF-2 (-806 to -786), CEBP- $\beta(-1505 /-1491$ and $-1443 /-1429)$, CDP repressor protein $(-105 /-87)$, GATA-1 $(-103 /-91)$ and an additional GRE $(-828 /-810)$, however further functional analysis is required to establish the relevance, if any, of these factors (Satyanarayana et al., 2011). The weak correlations between PXR, ARNT, and $H N F 1 \alpha$ genes with CYP2C19 mRNA expression in human liver suggests that these transcriptional regulators do not extensively contribute to CYP2C19 expression (Wang et al., 2011).

\section{Trans ACTING FACTORS}

In contrast to cis regulation due to genetic variants, the transacting factors which control CYP2C19 expression have been largely ignored. Knowledge of epigenomic control of CYP2C19, via factors such as altered expression of transcription factor genes or the effects of noncoding RNA, is limited. A number of studies have identified that environmental (rather than inherited genetic) effects such as pregnancy, old age, cancer, and congestive heart failure (Williams et al., 2000; Frye et al., 2002; McGready et al., 2003; Ishizawa et al., 2005) can all lead to an acquired alteration in CYP2C19 activity. The observed change in activity can lead to genotype-phenotype discordance, such that a poor metabolizer status can be observed in individuals who are not homozygous variant for null function alleles. This may be due to CYP2C19 gene down-regulation as has been observed following incubation of the inflammatory cytokines, IL- 6 and TGF- $\beta$, with primary human hepatocytes (Aitken and Morgan, 2007). The mechanisms for this down-regulation of CYP2C19 have not been elucidated to date but could include direct effects on gene transcription (e.g., CpG methylation), up-stream effects on the expression or activity of transcription factors or post-translational regulation of CYP2C19.

\section{EPIGENETICS}

Tissue specific regulation of genes can be the result of epigenetic regulation and it is notable that the expression of CYP2C19 is restricted to the liver and intestine (Läpple et al., 2003; Hayashi et al., 2011; Bourgine et al., 2012). Quantification of gene transcripts (cDNA copy number) indicates the same range and median expression of CYP2C19 mRNA in the intestine as in the liver. However, the authors could not detect an intra-individual correlation between CYP2C19 expression in samples of liver and intestine from each patient expression. Hence there may be independent regulation of transcription of CYP2C19 in these tissues (Läpple et al., 2003). One possible mechanism of tissue specific expression is epigenetic control via methylation of $\mathrm{CpG}$ islands in the gene or by histone modifications such as acetylation.

Remarkably little is known about epigenetic regulation of CYP2C19 (Ingelman-Sundberg et al., 2007). However a small number of $\mathrm{CpG}$ islands can be detected in the gene (Figure 2). Methylation of $\mathrm{CpG}$ sites in the promoter region of a target gene can affect the physical binding of transcription factors to regulate gene expression. In the case of CYP2C19 these $\mathrm{CpG}$ islands are not associated with the promoter region. However, DNA methylation can also act via an indirect mechanism on chromatin configuration. There is currently no data regarding the methylation status of the CYP2C19 CpG islands.

DNA methylation can lead to a phenomenon known as allelic expression imbalance. The difference in expression levels between two alleles of CYP2C19 typically occurs due to genetic polymorphisms (e.g., a heterozygous carrier of *3). However epigenetic silencing of an allele (e.g., methylation) can also result in the preferential expression of one of the two alleles. Allelic expression imbalance is assessed directly by the relative quantitation of an intragenic marker allele in cells or tissues. In the absence of any cis-acting control on transcription the allelic ratio should be 1

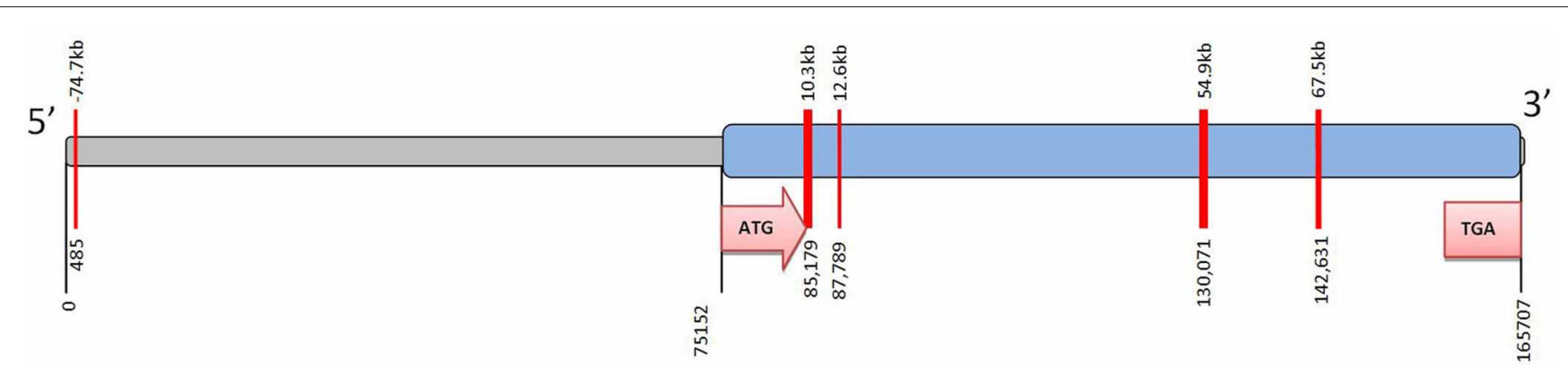

FIGURE 2 | CpG islands identified in CYP2C19. The complete CYP2C19 sequence (Ensembl Gene ID ENSG00000165841; National Centre for Biotechnology Information (NCBI); Entrez core nucleotide sequence NM 000769) was analyzed using CpG Island finder, http://cpgislands.usc.edu/. Potential $\mathrm{CpG}$ island regions were determined using the following parameters $\% \mathrm{GC}=50-55 \%$, ObsCpG/ExpCpG $=0.6$, length $=100-500 \mathrm{bp}$, gap between adjacent islands $=100 \mathrm{bp}$. Up to five $\mathrm{CpG}$ islands were identified in CYP2C19. Notably most of these CpG islands are down-stream of the ATG initiation codon (i.e., within the coding region of the gene) and are not associated with the 5'proximal promoter. The $\mathrm{CpG}$ islands are shown as red bars at $485,85179,87789,130071$, and $142631 \mathrm{bp}$. The $5^{\prime}$ upstream region is shown in grey and the coding region of the gene in blue. 
(i.e., equal amounts from each allele). In liver samples from heterozygous individuals, the cis-acting variant of CYP2C19 $(* 2$; rs4244285) accounts for the majority of the allelic expression imbalance observed. However, there was only a weak correlation ( $p=0.047$ ) between CYP2C19 mRNA expression and this SNP in these 96 human livers. This suggests that variability in CYP2C19 expression is not fully accounted for by known coding region polymorphisms. Interestingly, the non-coding marker SNP in intron 3, (rs 4388808), was associated with up to $47 \%$ of allelic expression imbalance for CYP2C19 (Wang et al., 2011). This confirms that in addition to cis-acting polymorphic variants, there are factors which influence the regulatory control of CYP2C19 RNA transcription or stability. Hence epigenetic factors may also affect the hepatic expression level of CYP2C19.

\section{POST-TRANSLATIONAL REGULATION OF CYP2C19}

In addition to transcriptional regulation, post-transcriptional regulation may influence the expression of CYP2C19. Noncoding RNA, such as microRNA (miR), can bind to recognition sites (MRE) in the $3^{\prime}$-untranslated region $\left(3^{\prime} \mathrm{UTR}\right)$ or in the coding region of target genes and thereby repress gene translation. The role of miR regulation of CYP2C19 was until recently not known, as in silico prediction of miR regulation of CYP2C19 was not available due to the lack of information about the $3^{\prime}$ UTR of the gene (Ramamoorthy and Skaar, 2011). However, it has recently been reported that the 3'UTR of CYP2C19 contains two putative MRE for miR-103/107 at 222-242 bp and 138-152 bp down-stream of the stop codon. These MRE contain one nucleotide mismatch, however, ectopic addition of precursors of miR-103/107 to human hepatocytes significantly downregulated CYP2C19 immunoreactive protein (Zhang et al., 2012). This preliminary data suggests that post-transcriptional regulation of the constitutive expression of CYP2C19 may be an additional contributing factor to inter-individual variation in the expression of this enzyme in subjects who do not express SNP variants.

\section{CONTROL OF TRANSCRIPTION FACTOR ACTIVITY}

Another mechanism which could account for variation in the regulation of CYP2C19 expression is the effect of both genomic and environmental factors which influence transcription factorbinding to the promoter region. SNP variants present in the promoter region have been discussed above, however up-stream

\section{REFERENCES}

Aitken, A. E., and Morgan, E. T. (2007). Gene-specific effects of inflammatory cytokines on cytochrome P450 2C, 2 B6 and 3A4 mRNA levels in human hepatocytes. Drug Metab. Dispos. 35, 1687.

Arefayene, M., Skaar, T. C., Zhao, X., Rae, J. M., Tanus-Santos, J. E., Brinkmann, U., et al. (2003). Sequence diversity and functional characterization of the $5^{\prime}$-regulatory region of human CYP2C19. Pharmacogenetgenomics 13, 199.
Baldwin, R., Ohlsson, S., Pedersen, R., Mwinyi, J., Ingelman-Sundberg, M., Eliasson, E., et al. (2008). Increased omeprazole metabolism in carriers of the CYP2C19*17 allele; a pharmacokinetic study in healthy volunteers. Br. J. Clin. Pharmacol. 65, 767-774.

Bauer, T., Bouman, H. J., Van Werkum, J. W., Ford, N. F., Ten Berg, J. M., and Taubert, D. (2011). Impact of CYP2C19 variant genotypes on clinical efficacy of antiplatelet treatment with

effects on the expression or activity of transcription factors may also play a role in CYP2C19 transcription. It is important to appreciate that as well as altered expression of transcription factor genes the function of ligand-activated factors (ER $\alpha, \mathrm{CAR}, \mathrm{GR}$ ) can be influenced by variation in the levels of endogenous ligands, such as estrogens and glucocorticoids. Hence environmental factors may influence the activity of transcription factors important for CYP2C19 transcription. The ability of ER $\alpha, \mathrm{CAR}, \mathrm{GR}, \mathrm{FOXA3}$, and GATA-4 to interact with other transcription factors may add further complexity to the regulation of CYP2C19. For example, estrogen-dependent activation of $\mathrm{ER} \alpha$ results in binding to the ERE. This appears to result in a down-regulation of CYP2C19 transcription (Mwinyi et al., 2010a). Changes in CYP2C19 activity have been reported in women during pregnancy and whilst using oral contraceptives (McGready et al., 2003), suggesting a regulatory role for estrogens on CYP2C19 activity. However, ligand-independent activation of $\mathrm{ER} \alpha$ also occurs. $\mathrm{ER} \alpha$ can act via a non-classical pathway to alter the activities of other transcription factors (e.g., Sp1, AP-1, or NF-kappaB) at their cognate sites on DNA. The role of interactions of ER- $\alpha$ with other transcription factors that regulate CYP2C19 cannot be discounted. This may account for why mutation constructs of the ERE site decrease but do not abolish CYP2C19 transcription in the presence of ligand activated ER- $\alpha$ (Mwinyi et al., 2010a). In addition, GATA-4 co-operates with FOXA3 to stimulate albumin gene transcription in liver cells (Cirillo et al., 2002). Moreover, FOXA3 and GATA-4 can act as pioneer factors. Once bound these pioneer factors relax the adjacent chromatin to allow other factors to bind. Interestingly GATA- 4 appears to be able to direct the association of ER $\alpha$ in certain contexts (Miranda-Carboni et al., 2011).

Understanding the genomic control of CYP2C19 expression is important in order to increase our understanding of the observed phenotype-genotype discordance in morbidity. This acquired deficiency may influence the sensitivity and specificity of CYP2C19 pharmacogenetic tests in clinical contexts. A correlation between CYP2C19 mRNA and the expression of CYP2C9 and CYP3A4 has been observed (Wang et al., 2011) and Bayesian network analysis suggests that CYP2C19 is the master regulator of CYP2C9, CYP3A7, CYP3A4, and CYP3A43 (Yang et al., 2010). Hence further study of the mechanisms which regulate CYP2C19 may also increase our understanding of the regulation of other important drug metabolizing enzymes.

clopidogrel: systematic review and meta-analysis. BMJ 343, d4588.

Begg, E. J., Helsby, N. A., and Jensen, B. P. (2012). Pharmacogenetics of drug-metabolizing enzymes: the prodrug hypothesis. Pharmacogenomics 13, 83-89.

Blaisdell, J., Mohrenweiser, H., Jackon, J., Ferguson, S., Coulter, S., Chanas, B., et al. (2002). Identification and functional characterization of new potentially defective alleles of human CYP2C19. Pharmacogenetics 12, 703-711.
Bort, R., Gómez-Lechón, M. J., Castell, J. V., and Jover, R. (2004). Role of hepatocyte nuclear factor $3 \gamma$ in the expression of human CYP2C genes. Arch. Biochem. Biophys. 426, 63-72.

Bourgine, J., Billaut-Laden, I., Happillon, M., Lo-Guidice, J.-M., Maunoury, V., Imbenotte, M., et al. (2012). Gene expression profiling of systems involved in the metabolism and the disposition of xenobiotics: comparison between human intestinal biopsy samples and colon 
cell lines. Drug Metab. Dispos. 40, 694-705.

Chen, Y., Ferguson, S. S., Negishi, M., and Goldstein, J. A. (2003). Identification of constitutive androstane receptor and glucocorticoid receptor binding sites in the CYP2C19 promoter. Mol. Pharmacol. 64, 316-324.

Choi, S.-Y., Koh, K. H., and Jeong, H. (2012). Isoform-specific regulation of cytochromes P450 expression by estradiol and progesterone. Drug Metab. Dispos. doi: 10.1124/dmd.112.046276. [Epub ahead of print].

Cirillo, L. A., Lin, F. R., Cuesta, I., Friedman, D., Jarnik, M., and Zaret, K. S. (2002). Opening of compacted chromatin by early developmental transcription factors HNF3 (FoxA) and GATA-4. Mol. Cell 9, 279-289.

De Morais, S., Wilkinson, G., Blaisdell, J., Meyer, U., Nakamura, K., and Goldstein, J. (1994a). Identification of a new genetic defect responsible for the polymorphism of (S)-Mephenytoin metabolism in japanese. Mol. Pharmacol. 46, 594-598.

De Morais, S., Wilkinson, G., Blaisdell, J., Nakamura, K., Meyer, U., and Goldstein, J. (1994b). The major genetic defect responsible for the polymorphism of S-Mephenytoin metabolism in humans. J. Biol. Chem. 269, 15419-15422.

Desta, Z., Zhao, X., Shin, J. G., and Flockhart, D. A. (2002). Clinical significance of the cytochrome P450 2C19 genetic polymorphism. Clin. Pharmacokinet. 41, 913-958.

Devendran, A., Uppugunduri, C. R. S., Sundaram, R., Shewade, D. G., Rajagopal, K., and Chandrasekaran, A. (2012). Relative copy number variations of CYP2C19 in south indian population. Mol. Biol. Int. 2012, 643856

Drögemöller, B. I., Wright, G. E., Niehaus, D. J., Koen, L., Malan, S., Da Silva, D. M., et al. (2010). Characterization of the genetic profile of CYP2C19 in two South African populations. Pharmacogenomics 11, 1095-1103.

Feng, H.-J., Huang, S.-L., Wang, W., and Zhou, H.-H. (1998). The induction effect of rifampicin on activity of mephenytoin $4^{\prime}$ hydroxylase related to $\mathrm{M} 1$ mutation of CYP2C19 and gene dose. $B r$. J. Clin. Pharmacol. 45, 27-29.

Ferguson, R., De Morais, S., Benhamou, S., Bouchardy, C., Blaisdell, J., Ibeanu, G., et al. (1998). A new genetic defect in human CYP2C19, mutation of the initiation codon is responsible for poor metabolism of S-Mephenytoin. J. Pharmacol. Exp. Ther. 284, 356-361.

Frye, R. F., Schneider, V. M., Frye, C. S., and Feldman, A. M. (2002). Plasma levels of TNF- $\alpha$ and IL- 6 are inversely related to cytochrome P450-dependent drug metabolism in patients with congestive heart failure. J. Card. Fail. 8, 315-319.

Fukushima-Uesaka, H., Saito, Y., Maekawa, K., Ozawa, S., Hasegawa, R., Kajio, H., et al. (2005). Genetic variations and haplotypes of CYP2C19 in a Japanese population. Drug Metab. Pharmacokinet. 20, 300-307.

Hayashi, M., Matsumoto, N., Takenoshita-Nakaya, S., Takeba, Y., Watanabe, M., Kumai, T., et al. (2011). Individual metabolic capacity evaluation of cytochrome P450 $2 \mathrm{C} 19$ by protein and activity in the small intestinal mucosa of japanese pancreatoduodenectomy patients. Biol. Pharm. Bull. 34, 71-76.

Helsby, N. A. (2008). Pheno-or genotype for the CYP2C19 drug metabolism polymorphism: the influence of disease. Proc. West. Pharmacol. Soc. 51, 5-10.

Helsby, N. A., Lo, W. Y., Sharples, K., Riley, G., Murray, M., Spells, K., et al. (2008). CYP2C19 pharmacogenetics in advanced cancer: compromised function independent of genotype. Br. J. Cancer 99, 1251-1255.

Hsu, H. L., Woad, K. J., Woodfield, D. G., and Helsby, N. A. (2008). A high incidence of polymorphic CYP2C19 variants in archival blood samples from Papua New Guinea. Hum. Genomics 3, 17-23.

Ibeanu, G., Blaisdell, J., Ferguson, R., Ghanayem, B., Brøsen, K., Benhamou, S., et al. (1999). A novel transversion in the intron 5 donor splice junction of CYP2C19 and a sequence polymorphism in exon 3 contribute to the poor metabolizer phenotype for the anticonvulsant drug S-Mephenytoin. J. Pharm. Exp. Ther. 290, 635-640.

Ibeanu, G., Blaisdell, J., Ghanayem, B., Beyeler, C., Benhamou, S., Bouchardy, C., et al. (1998a). An additional defective allele, CYP2C19*5, contributes to the S-Mephenytoin poor metabolizer phenotype in Caucasians. Pharmacogenetics 8, 129-135.

Ibeanu, G., Goldstein, J., Meyer, U., Benhamou, S., Bouchardy, C., Dayer, P., et al. (1998b). Identification of new human CYP2C19 alleles $($ CYP2C19*6 and $C Y P 2 C 19^{*} 2 B$ ) in a caucasian poor metabolizer of mephenytoin. J. Pharm. Exp. Ther. 286, 1490-1495.

Ingelman-Sundberg, M., Sim, S. C., Gomez, A., and Rodríguez-Antona, C. (2007). Influence of cytochrome P450 polymorphisms on drug therapies: pharmacogenetic, pharmacoepigenetic and clinical aspects. Pharm. Ther. 116, 496-526.

Ishizawa, Y., Yasui-Furukori, N., Takahata, T., Sasaki, M., and Tateishi, T. (2005). The effect of aging on the relationship between the cytochrome P450 2C19 genotype and omeprazole pharmacokinetics. Clin. Pharmacokinet. 44, 1179-1189.

Kaneko, A., Kaneko, O., Taleo, G., Björkman, A., and Kobayakawa, T. (1997). High frequencies of CYP2C19 mutations and poor metabolism of proguanil in Vanuatu. Lancet 349, 921-922.

Kawashima, S., Kobayashi, K., Takama, K., Higuchi, T., Furihata, T., Hosokawa, M., et al. (2006). Involvement of hepatocyte nuclear factor $4 \alpha$ in the different expression level between CYP2C9 and CYP2C19 in the human liver. Drug Metab. Dispos. 34, 1012-1018.

Kupfer, A., Desmond, P., Schenker, S., and Branch, R. (1979). Family study of a genetically determined deficiency of mephenytoin hydroxylation in man. Pharmacologist 21, 173.

Läpple, F., Von Richter, O., Fromm, M. F., Richter, T., Thon, K. P., Wisser, H., et al. (2003). Differential expression and function of CYP2C isoforms in human intestine and liver. Pharm. Genomics 13, 565-575.

Lee, S.-J., Kim, W.-Y., Kim, H., Shon, J.-H., Lee, S. S., and Shin, J.-G. (2009). Identification of new CYP2C19 variants exhibiting decreased enzyme activity in the metabolism of S-Mephenytoin and Omeprazole. Drug Metab. Dispos. 37, 2262-2269.

Li-Wan-Po, A., Girard, T., Farndon, P., Cooley, C., and Lithgow, J. (2010). Pharmacogenetics of CYP2C19, functional and clinical implications of a new variant CYP2C19*17. Br. J. Clin. Pharmacol. 69, 222-230.

Matimba, A., Del-Favero, J., Van Broeckhoven, C., and Masimirembwa, C. (2009). Novel variants of major drug-metabolising enzyme genes in diverse African populations and their predicted functional effects. Hum. Genomics 3, 169-190.

McGready, R., Stepniewska, K., Seaton, E., Cho, T., Cho, D., Ginsberg, A., et al. (2003). Pregnancy and use of oral contraceptives reduces the biotransformation of proguanil to cycloguanil. Eur. J. Clin. Pharmacol. 59, 553-557.

Miranda-Carboni, G. A., Guemes, M., Bailey, S., Anaya, E., Corselli, M., Peault, B., et al. (2011). GATA4 regulates estrogen receptor- $\alpha$ Mediated Osteoblast transcription. Mol. Endocrinol. 25, 1126-1136.

Molkentin, J. D. (2000). The zinc finger-containing transcription factors GATA-4, -5, and -6. J. Biol. Chem. 275, 38949-38952.

Morita, J., Kobayashi, K., Wanibuchi, A., Kimura, M., Irie, S., Ishizaki, T., et al. (2004). A novel single nucleotide polymorphism (SNP) of the CYP2C19 gene in a Japanese subject with lowered capacity of mephobarbital 4 -hydroxylation. Drug Metab. Pharmacokinet. 19, 236-238.

Mwinyi, J., Cavaco, I., Pedersen, R. S., Persson, A., Burkhardt, S., Mkrtchian, S., et al. (2010a). Regulation of CYP2C19 expression by estrogen receptor $\alpha$ : implications for estrogen-dependent inhibition of drug metabolism. Mol. Pharmacol. 78, 886-894.

Mwinyi, J., Hofmann, Y., Pedersen, R. S., Nekvindová, J., Cavaco, I., Mkrtchian, S., et al. (2010b). The transcription factor GATA-4 regulates cytochrome P4502C19 gene expression. Life Sci. 86, 699-706.

Ramamoorthy, A., and Skaar, T. C. (2011). In silico identification of MicroRNAs predicted to regulate the drug metabolizing cytochrome P450 genes. Drug Metab. Lett. 5, 126-131.

Rana, R., Chen, Y., Ferguson, S. S., Kissling, G. E., Surapureddi, S., and Goldstein, J. A. (2010). Hepatocyte nuclear factor $4 \alpha$ regulates rifampicin-mediated induction of CYP2C genes in primary cultures of human hepatocytes. Drug Metab. Dispos. 38, 591-599.

Romkes, M., Faletto, M. B., Blaisdell, J. A., Raucy, J. L., and Goldstein, J. A. (1991). Cloning and expression of complementary DNAs for multiple members of the human cytochrome P450IIC subfamily. Biochemistry 30, 3247-3255.

Satyanarayana, C. R. U., Devendran, A. Jayaraman, M., Mannu, J., Mathur, P. P., Gopal, S. D., et al. (2009a). Influence of the genetic polymorphisms in the 5' flanking and exonic regions of CYP2C19 on proguanil oxidation. Drug Metab. Pharmacokinet. 24, 537-548.

Satyanarayana, C. R. U., Devendran, A., Sundaram, R., Gopal, S. D., 
Rajagopal, K., and Chandrasekaran, A. (2009b). Genetic variations and haplotypes of the $5^{\prime}$ regulatory region of CYP2C19 in South Indian population. Drug Metab. Pharmacokinet. 24, 185-193.

Satyanarayana, C. R. U., Devendran, A., Satyamoorthy, K., Shewade, D. G., Krishnamoorthy, R., and Chandrasekaran, A. (2011). Functional characterization of promoter region polymorphisms of human CYP2C19 gene. Mol. Biol. Rep. 38, 4171-4179.

Scott, S. A., Martis, S., Peter, I., Kasai, Y., Kornreich, R., and Desnick, R. J. (2011). Identification of CYP2C19*4B: pharmacogenetic implications for drug metabolism including clopidogrel responsiveness. Pharmacogenomics J. 12, 297-305.

Sim, S. C., Risinger, C., Dahl, M. L., Aklillu, E., Christensen, M., Bertilsson, L., et al. (2006). A common novel CYP2C19 gene variant causes ultrarapid drug metabolism relevant for the drug response to proton pump inhibitors and antidepressants. Clin. Pharmacol. Ther. 79, 103-113.

Sistonen, J., Fuselli, S., Palo, J. U., Chauhan, N., Padh,
H., and Sajantila, A. (2009). Pharmacogenetic variation at CYP2C9, CYP2C19, and CYP2D6 at global and microgeographic scales. Pharmacogenet. Genomics 19, 170-179.

Wang, D., Jiang, Z., Shen, Z., Wang, H., Wang, B., Shou, W., et al. (2011). Functional evaluation of genetic and environmental regulators of P450 mRNA levels. PLoS ONE 6:e24900. doi: 10.1371/journal.pone.0024900

Williams, M. L., Bhargava, P., Cherrouk, I., Marshall, J. L., Flockhart, D. A., and Wainer, I. W. (2000). A discordance of the cytochrome P450 2C19 genotype and phenotype in patients with advanced cancer. Br. J. Clin. Pharmacol. 49, 485-488.

Wortham, M., Czerwinski, M., He, L., Parkinson, A., and Wan, Y.-J. Y. (2007). Expression of constitutive androstane receptor, hepatic nuclear factor $4 \alpha$, and P450 oxidoreductase genes determines interindividual variability in basal expression and activity of a broad scope of xenobiotic metabolism genes in the human liver. Drug Metab. Dispos. 35, 1700-1710.
Xiao, Z., Goldstein, J., Xie, H., Blaisdell, J., Wang, W., Jiang, C., et al. (1997). Differences in the incidence of the CYP2C19 polymorphism affecting the S-Mephenytoin phenotype in chinese han and bai populations and identification of a new rare CYP2C19 mutant allele. J. Pharmacol. Exp. Ther. 281, 604-609.

Xie, H., Kim, R., Wood, A., and Stein, C. (2001). Molecular basis of ethnic differences in drug disposition and response. Annu. Rev. Pharmacol. Toxicol. 41, 815-850.

Yang, X., Zhang, B., Molony, C. Chudin, E., Hao, K., Zhu, J., et al. (2010). Systematic genetic and genomic analysis of cytochrome P450 enzyme activities in human liver. Genome Res. 20 1020-1036.

Zhang, S.-Y., Surapureddi, S., Coulter, S., Ferguson, S. S., and Goldstein, J. A. (2012). Human CYP2C8 is post-transcriptionally regulated by MicroRNAs 103 and 107 in human liver. Mol. Pharmacol. 82, 529-540.

Zhou, Q., Yu, X. M., Lin, H. B., Wang, L., Yun, Q. Z., Hu, S. N., et al. (2009). Genetic polymorphism, linkage disequilibrium, haplotype structure and novel allele analysis of CYP2C19 and CYP2D6 in Han Chinese. Pharmacogenomics J. 9, 380-394.

Conflict of Interest Statement: The authors declare that the research was conducted in the absence of any commercial or financial relationships that could be construed as a potential conflict of interest.

Received: 23 August 2012; accepted: 24 September 2012; published online: 10 October 2012.

Citation: Helsby NA and Burns KE (2012) Molecular mechanisms of genetic variation and transcriptional regulation of CYP2C19. Front. Gene. 3:206. doi: 10.3389/fgene.2012.00206

This article was submitted to Frontiers in Pharmacogenetics and Pharmacogenomics, a specialty of Frontiers in Genetics.

Copyright (c) 2012 Helsby and Burns. This is an open-access article distributed under the terms of the Creative Commons Attribution License, which permits use, distribution and reproduction in other forums, provided the original authors and source are credited and subject to any copyright notices concerning any third-party graphics etc. 